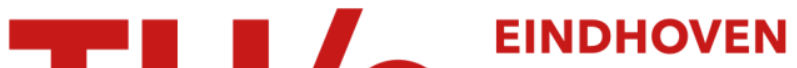 \\ UNIVERSITY OF \\ TECHNOLOGY
}

\section{Kinematics analysis of a robotic zipper prototype for miniaturisation}

\section{Citation for published version (APA):}

Baharom, M. Z., Delbressine, F. L. M., \& Feijs, L. M. G. (2016). Kinematics analysis of a robotic zipper prototype for miniaturisation. International Journal of Mechanical Engineering and Robotics Research, 5(4), 305-310. [14]. https://doi.org/10.18178/ijmerr.5.4.305-310

DOI:

10.18178/ijmerr.5.4.305-310

Document status and date:

Published: 04/10/2016

\section{Document Version:}

Publisher's PDF, also known as Version of Record (includes final page, issue and volume numbers)

\section{Please check the document version of this publication:}

- A submitted manuscript is the version of the article upon submission and before peer-review. There can be important differences between the submitted version and the official published version of record. People interested in the research are advised to contact the author for the final version of the publication, or visit the $\mathrm{DOI}$ to the publisher's website.

- The final author version and the galley proof are versions of the publication after peer review.

- The final published version features the final layout of the paper including the volume, issue and page numbers.

Link to publication

\section{General rights}

Copyright and moral rights for the publications made accessible in the public portal are retained by the authors and/or other copyright owners and it is a condition of accessing publications that users recognise and abide by the legal requirements associated with these rights.

- Users may download and print one copy of any publication from the public portal for the purpose of private study or research.

- You may not further distribute the material or use it for any profit-making activity or commercial gain

- You may freely distribute the URL identifying the publication in the public portal.

If the publication is distributed under the terms of Article 25fa of the Dutch Copyright Act, indicated by the "Taverne" license above, please follow below link for the End User Agreement:

www.tue.nl/taverne

Take down policy

If you believe that this document breaches copyright please contact us at:

openaccess@tue.nl

providing details and we will investigate your claim. 


\title{
Kinematics Analysis of A Robotic Zipper Prototype for Miniaturization
}

\author{
Mohamad Zairi Baharom ${ }^{1,2}$, Frank Delbressine ${ }^{1}$, and Loe Feijs ${ }^{1}$ \\ ${ }^{1}$ Designed Intelligence Group, Department of Industrial Design, P.O. Box 513, 5600MB Eindhoven, Netherlands \\ ${ }^{2}$ Faculty of Mechanical Engineering, Universiti Malaysia Pahang, 26600 UMP Pekan, Pahang, Malaysia \\ Email: \{m.z.baharom, fdelbres, 1.m.g.feijs\}@tue.nl, mohamadzairi@ump.edu.my
}

\begin{abstract}
This paper presents the mechanism and kinematics analysis of a robotic zipper prototype. This generic version of the robotic zipper is dedicated to automatically open and close the zipper which could be beneficial to elderly, people with physical disability, upper limb reduction deficiencies (ULRD), visual impairment, or developmental coordination disorder (DCD). The mechanism and kinematic analysis were conducted based on the working prototype build using Meccano. Results from this study are used to select the DC motor for the miniature model of this robotic zipper. Finally, the analysis managed to define the desired amount of DC motor torque and power for the miniature model and drive the robotic zipper to function as an assistive device for zipping or unzipping process.
\end{abstract}

Index Terms-kinematics, robotic zipper, miniaturization, elderly, physical disability

\section{INTRODUCTION}

Many devices have been designed to function as fasteners such as buckles, laces, safety pins and buttons for clothing. Formerly known as a clasp locker, a zipper is commonly used for binding the edges of an opening of fabric or other flexible material, like on a garment for example. Zippers can connect two pieces of fabric together. The zipper invention begins back in 1851, when Elias Howe, who invented the sewing machine, received a patent for an automatic, continuous clothing closure [1]. The first person to invent, conceive the idea of slide fastener and develop the working zipper is Whitcomb L. Judson [2], an American inventor from Chicago, back in 1893. Whitcomb's patent use the word 'clasp locker' instead of using the word 'zipper', which is a complicated hook-and-eye shoe fastener [2], [3]. In 1913, Gideon Sunback who was an electrical engineer designed the modern zipper and patented a design entitle 'separable fastener' in 1917 [4]. The design increased the number of fastening elements, introduced two-facing rows of elements that pulled into a single piece by the slider and also increased the opening for the elements guided by the slider. In 1937, the B.F Goodrich company then decided to use Gideon's fastener on a rubber boot and named the device as 'zipper' [5].

Manuscript received April 28, 2016; revised November 18 , 2016.
Dressing and undressing difficulties usually relate to people who are very sick and have a physical disability. These people who are unable to zip or unzip themselves will require assistance from others to perform the task. People with upper limb reduction deficiencies (ULRD) for example will have difficulties to use the zipper. In a study conducted by Vasluian et al., more than $50 \%$ of the youngsters with ULRD reported having problems to perform their daily life self-care activity of dressing and undressing and tying their shoelaces [6]. This group of people who live with only one arm, or did not have any arm, will have major consequences to execute their daily task. Besides that, people with myotonic muscular dystrophy [7], kind of degenerative disease which limits the use of hands can get some benefits too from the development of this robotic zipper. Most of our daily activities or tasks require the use of both hands no matter separately or together at one time. In a study related to patients with Parkinson's Disease (PD), few modifications have been suggested to change their approach to open or close the zippers [8]. PD patients will experience some dexterity on their body systems, activities and the fine motor development. They usually have issues with finger dexterity which will reduce their ability to use the zippers or fasten button themselves.

Visual impairment of elderly people will make it more difficult to use a zipper. Good eyesight is necessary to join the two separate zipper tapes and correctly pull the slider for the zipping or unzipping process. In the United Kingdom, $42 \%$ of people over 75 years will develop cataracts which will have symptoms of age-related macular degeneration [9]. Macular degeneration is a medical condition that usually affects older people and results in a loss of vision in the centre of the visual field. Other patients that could benefit from the invention of the robotic zipper are people with methylmalonic acidemia (MMA) and developmental coordination disorders (DCD). A survey found that 18 out of 31 MMA patients are unable to fasten (buttons, zippers, snaps) [10]. Developmental coordination disorder is a kind of disability found in children which their motor coordination problem will interfere their daily activities [11]. There is also a group of people who are facing difficulties to use buttons and zippers. A study conducted with 40 students with a goal to evaluate the effect of hand-eye coordination also include zippers in their training [12]. 
Therefore, the development of a robotic zipper could be a useful as an assistive device to assist disable and elderly people who are unable to independently use the zipper themselves. This project was inspired by a project by Adam Whiton, who build the first robotic zipper known as the Zipperbot [13]. The structure of the Zipperbot did not use the slider of the zipper to zip or unzip. Therefore, this newly-designed robotic zipper trying to remain the zipper structure as it is and develops a generic and universal type of this robot.

This paper explains the mechanism of a normal zipper itself and how this robotic zipper prototype works. The first working prototype for this project was constructed using Meccano. Meccano is a toy consisting of a set of plastic and metal parts which enables the building of working models, mechanical devices or prototypes. The kinematics of the mechanism based on the Meccano prototype has been analysed for the DC motor selection process for the miniature model.

\section{TERMINOLOGY AND MECHANISM}

\section{A. Zipper Terminology and Mechanism}

In order to successfully develop a correct mechanism for this robotic zippier, the understanding of the normal zipper structure and mechanism are essential. The three main parts of a zipper are elements, slider and tape. Based on ASTM D2050-04 International standard [14], Fig. 1 shows the principal parts of the zipper and standard terminology relating to subassemblies of the zipper. Elements are devices designed for interlocking, capable of being affixed along the edge of a tape. The slider is the part that opens a zipper when it is moved in one direction and closes the zipper when it is moved in the opposite direction. The tape is a strip of material along one edge of which the bead and elements are attached.

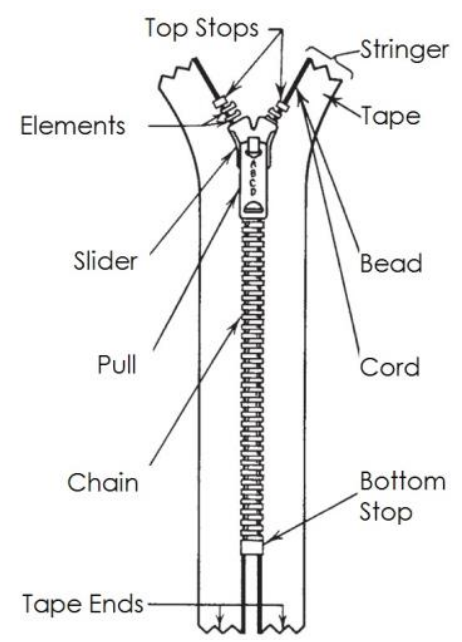

Figure 1. Principal parts of zipper [14].

Showing in Fig. 2 is the structure of a slider. The standard terminology of this slider structure is based on ASTM D2050-04 as relating to subassemblies of zippers [14]. The pull is a part connected to a zipper slider by which the slider is operated. This pull is attached to a portion of the slider which called the bail. The flanges are the slide's inclined edges that push the teeth towards each other. The throat is the two openings in a slider that receive the tape halves with the teeth. Meanwhile, the diamond is the wedge-shaped portion of a slider between the throats.

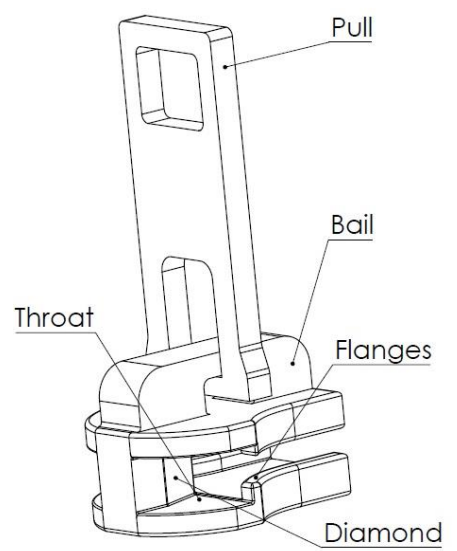

Figure 2. The standard terminology of the slider structure.

According to [5], [7], a zipper is a slide fastener consisting of interlockable elements, each attached to one of the opposing edges of two tapes and a movable part which is called a "slider". It spans the interlockable elements, which when moving in one direction cause the elements on one tape half to interlock with the elements on the other tape half, and when moved in the opposite direction causes the elements to disengage.

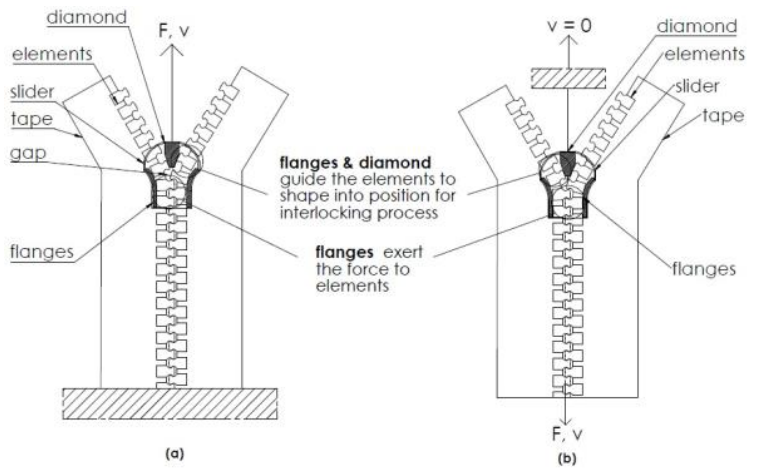

Figure 3. Zipper closing mechanism diagram.

Fig. 3 shows the zipper closing mechanism. As the slider moves up in Fig. 3(a) and the zipper tape is fixed, it pushes the elements to enter the slider throat together at specific angles. The force extended by the lower wedge is perpendicular to its movement direction. As the tape moves through the slider, the lower wedge inclined edges pushed the elements towards each other and latched into a gap on the opposite side. It is the same process as in Fig. 3(b) when the zipper tape is being pulled from the bottom, and the slider is fixed. This condition will also complete the zipper closing operation. When the slider has been pulled down as in Fig. 4(a) and the tape is fixed, the diamond pushed against the slanted edged of the elements and pivoting each element off. Then, both sides of the zipper are detached. This operation also can be done by fixing the slider and pull both sides of the zipper tape as shown in Fig. 4(b). 


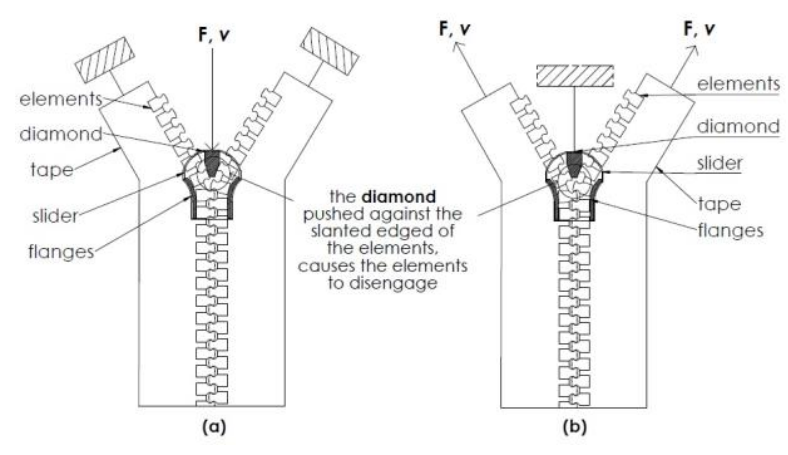

Figure 4. Zipper opening mechanism diagram.

\section{B. Prototype Mechanism}

Prototyping is critical to the success of the product development effort [15]. Showing in Fig. 5 is the 3D view of the first working prototype. It defines the position of important parts which are the slider, pull, tape, elements and gear sprocket. This first prototype dimension is $61 \times 35 \times 50 \mathrm{~mm}$, and was built using Meccano parts. It used two gear sprockets as traction mechanism on both sides of the tape to establish the uniform distribution of normal force acting towards the zipper tape.

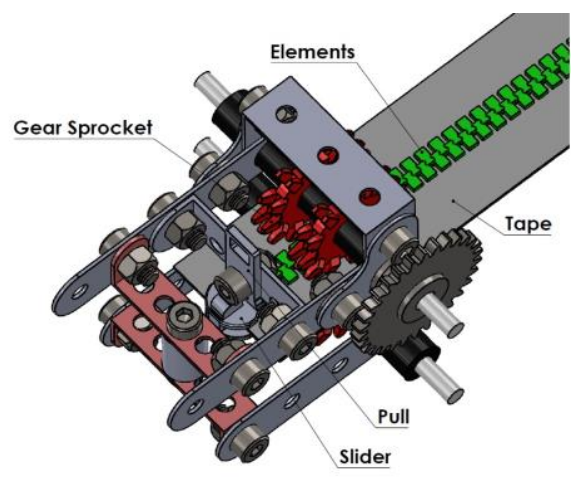

Figure 5. 3D view of the Meccano working prototype.

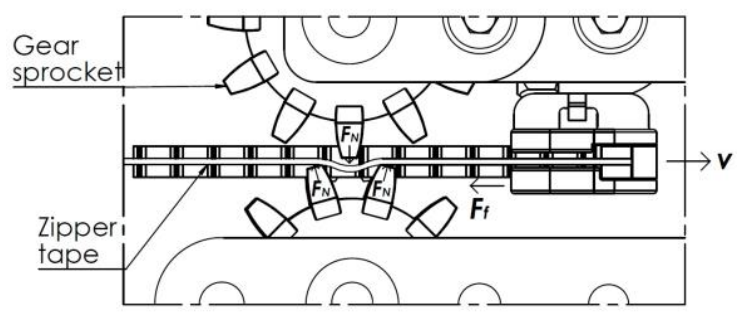

Figure 6. Close view of the gear sprocket and zipper tape engagement.

Fig. 6 shows the normal force, $F_{N}$ and friction force, $F_{f}$ acting on the zipper tape as it travels with velocity, $v$. To push or pull the slider, this mechanism requires good traction. In general, traction refers to "frictional forces that beneficially transmit mechanical power through a contact, with one body driving another" [16]. It can be seen from Fig. 6 that the gear sprocket from top and bottom side of the prototype make contact on the zipper tape surface and generate traction. The gear tooth grab the zipper tape. This occurs by direct contact between the surface asperities.
Friction is an important factor in producing good traction [16]. When the other surface is relatively soft or flexible which is the case for the tape halves to the rotating wheels, the major source of friction comes from the plowing effect. In this case, the gear sprocket tooth sinks into the zipper tape as it is a flexible material and must push or plough its way through. The ploughing effect relates to the relative height of surface asperities, while adhesion effect related to the true area of contact. Gear sprocket and zipper tape surface must have sufficient friction and contact area between them to ensure the grip is strong enough. Friction is a reaction force needed to produce traction.

\section{KINEMATICS ANALYSIS}

Fig. 7 shows the free body diagram for the upward motion of the robotic zipper with two wheels rotating on the zipper tape surface. Wheel A is the driven wheel, while wheel B works as the following wheel. Sufficient normal force $F_{N}$ is essential to ensure friction occurred between the wheel and zipper tape, thus generates the traction. The pulling force, $F_{\text {pull }}$ is the force required to pull the zipper tape, while $F_{A}$ and $F_{B}$ are the friction forces between the wheel $\mathrm{A}$ and $\mathrm{B}$ with the zipper tape surface, respectively. The $\omega_{A}$ and $\omega_{B}$ are the angular velocities of both wheels $\mathrm{A}$ and $\mathrm{B}$. The $r, v$ and $W$ in this diagram stand for the radius of the wheel, velocity, and total weight of this robotic zipper, respectively.

The movement of this robotic zipper has been considered in the vertical climbing position as the optimum condition. Considering this system is in static equilibrium, the summation of forces in $x$ and $y$-axis are equal to zero as in Newton's first law [17], as described in (1) and (2).

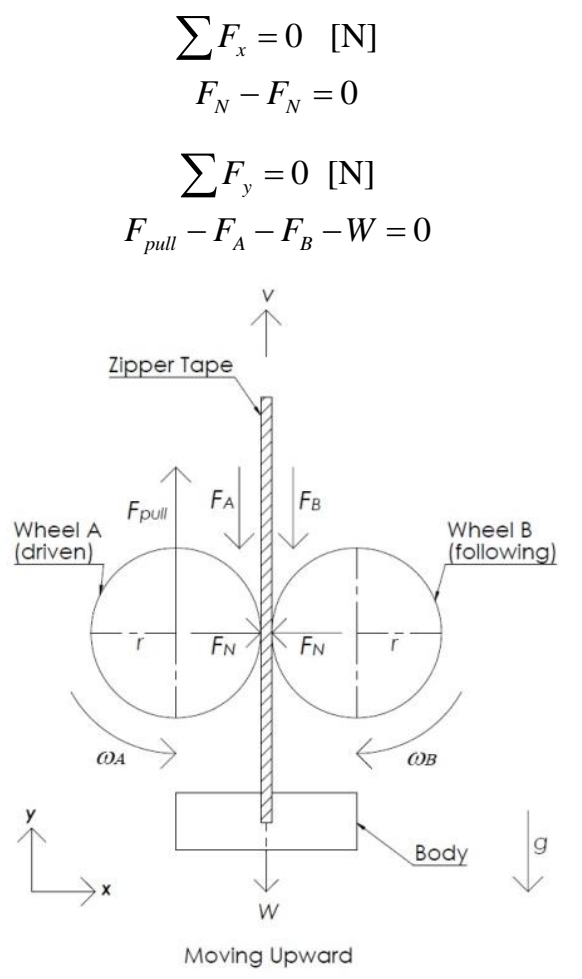

Figure 7. Free body diagram for upward motion of the slider. 
Both wheels are identical in size and material. Hence, $F_{A}$ is equal to $F_{B}$ and both frictional forces are now considered as $F_{f}$. Therefore, (2) becomes

$$
\begin{gathered}
F_{\text {pull }}-2 F_{f}-W=0[N] \\
F_{\text {pull }}=2 F_{f}+W
\end{gathered}
$$

The torque, $T$ equation is expressed by (4)

$$
\begin{aligned}
T & =F . r[\mathrm{~N} . \mathrm{m}] \\
& =F_{\text {pull }} \cdot r
\end{aligned}
$$

Introducing (3) into equation (4), defines the upward torque, $T_{\text {upward }}$ as

$$
\begin{gathered}
T_{\text {upward }}=F \cdot r[\mathrm{~N} . \mathrm{m}] \\
=F_{\text {pull }} \cdot r \\
=\left(2 F_{f}+W\right) \cdot r
\end{gathered}
$$

The power, $P$ is given by (6)

$$
P=T . \omega[\text { Watts }]
$$

which by inserting (5) into (6), the power of upward motion, $P_{\text {upward }}$ now is

$$
\begin{gathered}
P_{\text {upward }}=T \cdot \omega \text { [Watts] } \\
=\left(2 F_{f}+W\right) \cdot r \cdot \omega
\end{gathered}
$$

Fig. 8 illustrates the free body diagram of this robotic zipper during its downward movement. It is obviously can be seen from the diagram that the direction of $F_{\text {pull }}$ is currently parallel with the total body weight, $W$ of this robotic zipper. This body weight defined as the force of gravity, which will help to reduce the amount of pulling force required for downward motion, and can be calculated as the mass times the acceleration of gravity. In the static equilibrium during the downward motion, the summation of forces in $x$ and $y$-axis is equal to zero as in (8) and (9).

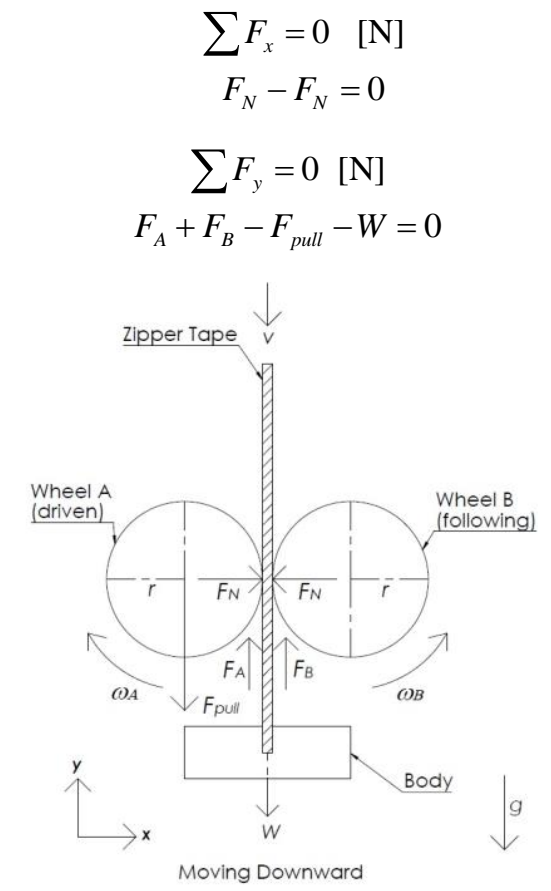

Figure 8. Free body diagram for downward motion of the slider.
As the previous calculation during the upward motion, $F_{A}$ is equal to $F_{B}$ since both are identical wheels, and again the frictional forces now referred as $F_{f}$. Thus, the (9) is now

$$
\begin{gathered}
2 F_{f}-F_{\text {pull }}-W=0[\mathrm{~N}] \\
F_{\text {pull }}=2 F_{f}-W
\end{gathered}
$$

The downward torque, $T_{\text {downward }}$ can be determined by introducing (10) to (4), which will give

$$
\begin{gathered}
T_{\text {downward }}=F \cdot r[\mathrm{~N} \cdot \mathrm{m}] \\
=F_{\text {pull }} \cdot \mathrm{r} \\
=\left(2 F_{f}-W\right) \cdot \mathrm{r}
\end{gathered}
$$

and by filling in (10) to (6) will define the power for downward motion, $P_{\text {downward }}$ as

$$
\begin{gathered}
P_{\text {downward }}=T . \omega[\text { Watts] } \\
=\left(2 F_{f}-W\right) . r . \omega
\end{gathered}
$$

Since wheel A drive the following wheel of B, the assumption is both wheels rotate at the same angular velocity. Consequently, the $\omega_{A}$ is equal to $\omega_{B}$. Therefore, the angular velocity is now considered as $\omega$. The relation between the velocity, $v$, angular velocity, $\omega$ and the wheel radius, $r$, is given by (13)

$$
\begin{gathered}
v=\omega . r[\mathrm{~m} / \mathrm{s}] \\
r=\frac{v}{\omega}
\end{gathered}
$$

In order to express both upward and downward torque and power regarding the velocity, $v$ and angular velocity, $\omega$, it can be achieved by filling in (13) to (5) and (11). Thus, the equation will be

$$
\begin{gathered}
T_{\text {upward }}=F \cdot r[\mathrm{~N} \cdot \mathrm{m}] \\
=F_{\text {pull }} \cdot r \\
=\left(2 F_{f}+W\right) \cdot r \\
=\left(2 F_{f}+W\right) \cdot \frac{v}{\omega} \\
T_{\text {downward }}=F \cdot r[\mathrm{~N} \cdot \mathrm{m}] \\
=F_{\text {pull }} \cdot r \\
=\left(2 F_{f}-W\right) \cdot r \\
=\left(2 F_{f}-W\right) \cdot \frac{v}{\omega}
\end{gathered}
$$

and by introducing (13) to (7) and (12), the power during upward and downward motion in terms of velocity, $v$ and angular velocity, $\omega$ is

$$
\begin{gathered}
P_{\text {upward }}=T \cdot \omega \text { [Watts] } \\
=\left(2 F_{f}+W\right) \cdot r \cdot \omega \\
=\left(2 F_{f}+W\right) \cdot r \cdot \frac{v}{r} \\
=\left(2 F_{f}+W\right) \cdot v
\end{gathered}
$$




$$
\begin{gathered}
P_{\text {downward }}=T \cdot \omega \text { [Watts] } \\
=\left(2 F_{f}-W\right) \cdot r \cdot \omega \\
=\left(2 F_{f}-W\right) \cdot r \cdot \frac{v}{r} \\
=\left(2 F_{f}-W\right) \cdot v
\end{gathered}
$$

\section{RESUlTS AND DisCUSSION}

The required force to pull the robotic zipper were measured. A force gauge was used to measure the pulling force, $F_{\text {pull }}$ in two different conditions as depicted in Table I.

TABLE I. ForCE MEASUREMENT DATA

\begin{tabular}{|l|c|}
\hline \multicolumn{1}{|c|}{ Condition } & Force amount [N] \\
\hline Pulling the zipper only & 2.05 \\
\hline Pulling the zipper with the wheels & 4.20 \\
\hline
\end{tabular}

The measured friction force was $2.15 \mathrm{~N}$. This system moves with velocity, $v$ of $0.04 \mathrm{~m} / \mathrm{s}$, which is based on the speed of the zipperbot. This robotic zipper will be a wearable on cloth, and its current size of $61 \times 35 \times 50 \mathrm{~mm}$ is too big. Therefore, the formulation from (14) to (17) in the previous section will be used as the guidance for DC motor selection of the miniature model. The DC motor selection for the miniature model will consider parameters as listed below in Table II.

TABLE II. PARAMETERS FOR MiniATURE MODEL

\begin{tabular}{|l|c|}
\hline \multicolumn{1}{|c|}{ Item } & Value \\
\hline Pulling force, $F_{\text {pull }}[\mathrm{N}]$ & 4.20 \\
\hline Wheel radius, $r[\mathrm{~mm}]$ & 4.00 \\
\hline Velocity, $v[\mathrm{~m} / \mathrm{s}]$ & 0.04 \\
\hline Weight, $W[\mathrm{~g}]$ & 49.5 \\
\hline
\end{tabular}

Table III summarizes the calculation results on torque, speed (rpm) and power based on using pulling force as $4.20 \mathrm{~N}$, wheel radius of $4 \mathrm{~mm}$ and a speed of $0.04 \mathrm{~ms}^{-1}$ using formulation in the previous section. Based on this result, the amount of torque needed is $19.14 \mathrm{mNm}$, with the speed of $95.4 \mathrm{rpm}$ and power of $191.4 \mathrm{~mW}$. These values will be used as the reference for the DC motor selection of the miniature model of this robotic zipper project, which is in the dimension of $40 \times 30 \times 24.5 \mathrm{~mm}$.

TABLE III. THE CALCULATION SUMMARY

\begin{tabular}{|c|c|c|}
\hline \multirow{2}{*}{ Parameter } & \multicolumn{2}{|c|}{ Direction } \\
\cline { 2 - 3 } & Upward & Downward \\
\hline Torque $[\mathrm{mNm}]$ & 19.14 & 15.26 \\
\hline Speed $[\mathrm{rpm}]$ & 95.4 & 95.4 \\
\hline Power $[\mathrm{mW}]$ & 191.4 & 191.4 \\
\hline
\end{tabular}

Based on the formulation in (14) and (15) and results in Table III, it can be clearly seen that much higher torque is needed during the upward motion of this robotic zipper, compared to the downward motion. The higher the torque, the higher power required. This happens because during the upward motion, the robotic zipper will have to pull the weight of its body. Meanwhile, during the downward motion, the existence of gravitational force from the body's weight helps to reduce the amount of pulling force, where it will also decrease the desired amount of torque and power. The final velocity of this robotic zipper will also influence the selection process for the motor since this parameter relation with the desired amount of torque and power is directly proportional. The results in Table III indicated that the desired amount of torque needed is $19.14 \mathrm{mNm}$, with a speed of $95.4 \mathrm{rpm}$ and power of $191.4 \mathrm{~mW}$, to drive the miniature model of this robotic zipper.

\section{CONCLUSION}

This paper presented the mechanism and kinematics analysis of the robotic zipper prototype. The results demonstrated the amount of torque and power required for the miniature model of the robotic zipper. Moving upward will require a higher torque compared to the downward motion due to the weight carried by this robotic zipper. Besides that, sufficient normal force is needed to ensure both top and bottom wheels of this robotic zipper contacted with each other and grab the fabrics in between. Friction is also an important factor to produce good traction for this system. This achievement is a step further to create a miniature model of robotic zipper which in turn can be an assistive device for elderly and disabled people to use zippers.

\section{ACKNOWLEDGMENT}

The authors would like to express their gratitude and special acknowledgements to the Ministry of Higher Education Malaysia (MoHE) and Universiti Malaysia Pahang (UMP) for the Ph.D programs funding of Mohamad Zairi Baharom. In addition, a special acknowledgement to Marina Toeters from bywire.net for her support and contribution towards this project. Also for staff members of D.Search lab, Department of Industrial Design, Eindhoven University of Technology, for their kind support during the fabrication process of the robotic zipper prototype.

\section{REFERENCES}

[1] E. Howe, "Improvement in fastenings for garments," U.S. Patent 8540, November 25, 1851.

[2] W. L. Judson, "Shoe-fastening," U.S. Patent 504037, August 29, 1893.

[3] R. Shaw and C. Grall, Great Inventors and Inventions, Wizard Books, 2003.

[4] G. Sundback, “Separable fastener,” U.S. Patent 1219881, March 20, 1917.

[5] Ansun Multitech. The history of zipper. [Online]. Available: http://www.ansun.com/

[6] E. Vasluian, I. Van Wijk, P. U. Dijkstra, H. A. Reindersmesselink, and C. K. Van Der Sluis, "Adaptive devices in youngsters with upper limb reduction deficiencies: Use and satisfaction," Journal of Rehabilitation Medicine, 2014.

[7] D. Balon, "Facts about myotonic muscular dystrophy," Muscular Dystrophy Association, 2011.

[8] N. I. Mady and S. M. Atiha, "Taking advantage of ergonomics in clothing design to improve quality of life for people with Parkinson's Disease," Canadian Symposium XIII on Home 
Economics / Home Ecology / Family Studies Education, pp. 6069, 2015.

[9] K. Flynn and C. Lord, "Living with sight loss: Updating the national picture," RNIB NatCen, 2015.

[10] Y. P. Ktena, S. M. Paul, N. S. Hauser, J. L. Sloan, A. Gropman, I. Manoli, and C. P. Venditti, "Delineating the spectrum of impairments, disabilities, and rehabilitation needs in methylmalonic acidemia (MMA)," American Journal of Medical Genetics. Part A, vol. 167, no. 9, pp. 2075-2084, 2015.

[11] J. G. Zwicker, C. Missiuna, S. R. Harris, and L. A. Boyd, "Developmental coordination disorder: A review and update," European Journal of Paediatric Neurology, vol. 16, no. 6, pp. 573-581, 2012.

[12] S. A. Uysal and T. Dúger, "Effect of hand-eye coordination and daily living activities' training on quality of life and functional vision in students with low vision," Journal of Exercise Therapy and Rehabilitation, vol. 1, no. 2, pp. 62-67, 2014.

[13] A. Whiton, "Methods and apparatus for robotic zipper," U.S. Patent 2015/0082582A1, March 26, 2015.

[14] ASTM Standard D2050-04, "Standard Terminology Relating to Subassemblies," ASTM International., 2010, pp. 1-5.

[15] ASTM Standard D123-03, "Standard Terminology Relating to Textiles," ASTM International, 2003.

[16] Q. Wang and Y. Chung, Encyclopedia of Tribology, New York: Springer, 2013, pp. 3713-3714.

[17] H. Young and R. Freedman, University Physics with Modern Physics, 13th ed. San Francisco: Pearson, 2007.

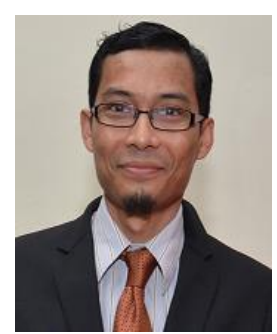

Mohamad Zairi Baharom received his Bachelor in Mechanical Engineering (Industry) from Universiti Teknologi Malaysia (UTM), Malaysia in 2007. He then obtained his M.Sc in Mechanical Engineering in 2013 from Universiti Kebangsaan Malaysia (UKM), Malaysia. He joined Universiti Malaysia Pahang, Malaysia as lecturer at Faculty of Mechanical Engineering. $\mathrm{He}$ is currently pursuing his $\mathrm{PhD}$ at Department of Industrial
Design, Eindhoven University of Technology (TU/e), Netherlands. He is a member of the Board of Engineers Malaysia (BEM) and Science and Engineering Institute (SCIEI). His research areas are about industrial design and wearables.

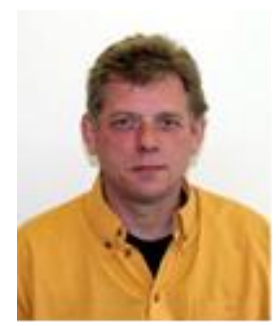

Frank Delbressine received his $\mathrm{PhD}$ in Mechanical Engineering from the Eindhoven University of Technology, The Netherlands in 1989. He is currently an assistant professor at the Department of Industrial Design of the Eindhoven University of Technology. His main research interests are Medical Simulation, wearables and autonomous vehicles.

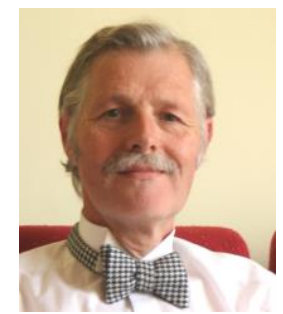

Loe Feijs has an M.Sc. in electrical engineering and a Ph.D. in computer science from Eindhoven University of Technology. In the 1980s he worked on video compression and telephony systems. He joined Philips Research to develop formal methods for software development. In 1994 he became part-time professor of Mathematics and Computer Science, in 1998 scientific director of the Eindhoven Embedded Systems Institute, and in 2000 vice dean of the new department of Industrial Design at TU/e, Eindhoven. At present he is professor for Industrial Design of Embedded Systems. Feijs is the author of three books on formal methods and of over 100 scientific papers. 